OPEN ACCESS

Edited by:

Małgorzata Lipowska University of Gdańsk, Poland

Reviewed by: Katarzyna Sitnik-Warchulska, Jagiellonian University, Poland Jolanta Jonak Northeastern Illinois University, United States

*Correspondence: Shervin Assar assari@umich.edu

Specialty section: This article was submitted to Educational Psychology, a section of the journal

Frontiers in Education

Received: 20 January 2020 Accepted: 12 March 2020 Published: 09 April 2020

Citation: Assari S, Boyce S, Bazargan M, Caldwell $\mathrm{CH}$ and Zimmerman MA (2020) Place-Based Diminished Returns of Parental Educational Attainment on School Performance of Non-Hispanic White Youth. Front. Educ. 5:30

doi: 10.3389/feduc.2020.00030

\section{Place-Based Diminished Returns of Parental Educational Attainment on School Performance of Non-Hispanic White Youth}

\author{
Shervin Assari ${ }^{*}$, Shanika Boyce ${ }^{2}$, Mohsen Bazargan ${ }^{1,3}$, Cleopatra H. Caldwell ${ }^{4}$ and \\ Marc A. Zimmerman ${ }^{4}$ \\ 'Department of Family Medicine, College of Medicine, Charles R. Drew University of Medicine and Science, Los Angeles, \\ CA, United States, ${ }^{2}$ Department of Pediatrics, College of Medicine, Charles R. Drew University of Medicine and Science, \\ Los Angeles, CA, United States, ${ }^{3}$ Department of Health Behavior and Health Education, University of Michigan School \\ of Public Health, Ann Arbor, MI, United States, ${ }^{4}$ Department of Family Medicine, University of California, Los Angeles, Los \\ Angeles, CA, United States
}

Background: Youth educational outcomes are a function of a wide range of factors including parental education level. This effect, however, is shown to be smaller for African American, Hispanic, and Asian American youth, a pattern called Marginalizationrelated Diminished Returns (MDRs). It is, however, unknown if it is race/ethnicity or other conditions associated with race/ethnicity (e.g., poor neighborhood quality) which reduces the marginal returns of parental education for youth.

Aim: To explore whether MDRs are only due to race/ethnicity or if they also remain for non-Hispanic Whites in poor neighborhoods, we compared the association between parental education level and adolescents' school performance based on neighborhood quality in a nationally representative sample of non-Hispanic Whites in the United States.

Methods: This cross-sectional study used wave 1 of the Add Health study, an ongoing nationally representative cohort, 1994-2019. Participants included 849 non-Hispanic White adolescents between the ages of 12 and 21 years and their parents. The independent variable was parental education level, which was treated as a continuous measure. Age, grade, gender, and parental marital status were the covariates. The dependent variable was school performance (sum of school grades in Math, English, History, and Science). Linear regression models were used for data analysis.

Results: Overall, worse neighborhood quality was associated with worse school performance. Parental education level, however, was not directly associated with youth school performance. We found a statistically significant interaction between parental education level and neighborhood quality suggesting that the strength of the association between parental education and youth school performance weakens as neighborhood quality declines. 
Conclusion: Parental education level is a more salient determinant of youth educational outcomes in better neighborhoods. The result suggests that MDRs may not be solely due to race/ethnicity but contextual factors that commonly covary with marginalization and poverty. These contextual factors may include segregation, concentration of poverty, and social and physical neighborhood disorder.

Keywords: socioeconomic position, socioeconomic status, education, adolescents, youth, education, GPA

\section{INTRODUCTION}

Educational and developmental outcomes are worse for youth from non-marginalized compared to the non-marginalized background (Messiah et al., 2013; Butler, 2017; Guglielmo et al., 2018). Research, for example, has established worse educational outcomes for African American (AA) and Hispanic than non-Hispanic White youth (Arellano et al., 1998; Albrecht and Gordon-Larsen, 2013). Similarly, youth from families with lower socioeconomic status (SES) also report worse educational and developmental outcomes than high SES youth (Arellano et al., 1998; Albrecht and Gordon-Larsen, 2013; Benjet et al., 2009). These patterns can be seen for physical health (Butler, 2017), psychological well-being (Malhotra et al., 2015; Assari and Caldwell, 2017), aggression (Wallace et al., 2009; Basch, 2011), risk behaviors (Wallace et al., 2009; Basch, 2011), and school performance (Arellano et al., 1998; Basch, 2011). Socially marginalized youth are at risk for poor school performance (Chavous et al., 2008).

The mechanisms by which marginalized youth report worse educational and developmental outcomes have not been well understood. Racial/ethnic minority and low SES (e.g., parental education) individuals are particularly at risk of poor school performance (Carlo et al., 2011; Butler, 2017). Although researchers have attempted to decompose the effects of race/ethnicity and SES to social and developmental inequalities (Lau et al., 2012; Rossen and Schoendorf, 2012; Jones, 2018), these attempts have not generated conclusive results.

One of the proposed mechanisms for worse developmental and educational outcomes in marginalized youth is exposure to high levels of adversity and low level of SES resources in impoverished low-quality neighborhoods (Carlo et al., 2011; Butler, 2017). In this view, place should be seen as an explanatory mechanism for why socially marginalized youth develop suboptimal outcomes (Assari and Lankarani, 2016). Researchers, however, have proposed a complementary mechanism (i.e., differential effects) (Assari and Lankarani, 2016). Based on Marginalization-related Returns (MDRs), the effects of SES indicators particularly parental education on generating tangible economic, developmental, and health outcomes, are smaller for marginalized rather than socially privileged families (Assari, 2017, 2018a). Several examples have shown that parental education generates fewer positive outcomes for racial and ethnic minority (Assari, 2017, 2018a). MDRs suggest that not all of the worse outcomes in marginalized people are due to lower SES but also lower marginal returns of available SES resources for disenfranchised groups (Assari, 2017, 2018a). The MDRs literature, however, has not previously defined marginalization based on the neighborhood quality.

For youth educational outcomes, parental education is one of the most significant resources that shape youth educational (Mercy and Steelman, 1982; Davis-Kean, 2005) and health (Wills et al., 1995; Appleton-Arnaud, 2008; Ali and Elsayed, 2018) outcomes. In line with MDRs framework, however, researchers have documented smaller health gains from parental educational attainment for AA than non-Hispanic White adolescents (Assari, 2018b,c; Assari and Hani, 2018; Assari et al., 2018a,b,e). Diminished returns of parental education level are shown for AA youth in the areas of attention deficit hyperactivity disorder (Assari and Caldwell, 2019), self-rated health (Assari, 2018c), anxiety (Assari et al., 2018c), depression (Assari and Caldwell, 2018; Assari et al., 2018d), smoking (Bachman et al., 2011), aggression (Assari et al., 2020a), impulse control (Assari et al., 2018a), school attainment/performance (Assari, 2018b, 2019d), and school bonding (Assari, 2019c). This literature, however, is bound by the definition of marginalization based on race/ethnicity. As such, we have limited research on how place can marginalize individuals and reduce gains from available resources (i.e., similar to MDRs due to race/ethnicity). Place is the major context in which families live in, thus it can generate MDRs through shaping access to available resources and opportunities (Prentice and Jebb, 2003; Li et al., 2009; Blok et al., 2015; Patel et al., 2017). In the case of educational outcomes, school quality widely varies across neighborhoods (Sisco et al., 2015; Mackenbach et al., 2017). Worse neighborhoods, segregated areas, stressful places, and resource-scarce places can all interfere with application of resources as well as actualization of potentials. Although place can generate diminished returns, place-based MDRs are rarely studied. While MDRs are historically overlooked as a mechanism for health inequalities (Assari, 2017, 2018a), this is even worse for contexts in which MDRs emerge. Most research on social inequalities have focused on direct effects of neighborhoods (i.e., differential exposure hypothesis) which means that neighborhoods, adversities, or resources would mediate social inequalities. Studying MDRs, however, requires testing how context and neighborhood reduces the marginal return of available resources (e.g., parental education) on outcomes (e.g., youth school performance).

\section{Aim}

Building on the MDRs literature (Assari, 2017, 2018a) and using a national sample of United States adolescents (Hyland et al., 2017; Tourangeau et al., 2018), we compared the effect of parental 
education level on adolescents' educational outcomes based on neighborhood quality. The unique contribution of this study is that it expands the MDRs literature from a literature almost exclusively focused on racial and ethnic differences (Assari et al., 2018a,b,e) to include effects of marginalization based on place. We hypothesize that MDRs would be relevant based on place meaning that the effects of parental educational attainment on youth school performance are expected to be weaker in lowresource neighborhoods. Although neighborhood has various aspects, we could only look at perceived neighborhood quality. We had data on perceptions of garbage and drugs in the neighborhood as an indicator of poor-quality neighborhoods (social disorder).

We argue that MDRs may not be only relevant to race/ethnicity but any type of marginalization (based on place in this paper). As a result, we hypothesize that MDRs may be even relevant to White youth who are socially marginalized and live in low-quality neighborhoods. Due to the social stratification, we expect MDRs of parental education for families who reside in neighborhoods with low quality. Built on MDRs, we define marginalization based on place; poor neighborhood quality may be associated with fewer returns for non-Hispanic Whites. If we find support for our hypothesis, neighborhood and context may explain poor outcomes in race/ethnic minority families, across SES levels.

\section{MATERIALS AND METHODS}

\section{Design and Settings}

This secondary analysis borrowed the existing wave 1 data of the National Longitudinal Study of Adolescent Health (Add Health) study, 1994-2019 (ongoing). Add Health has enrolled a nationally representative sample of American youth. The study was designed and conducted by University of North Carolina to better understand contextual determinants of health, behaviors, and outcomes of adolescents and young adults in the United States. Time 1 data collection of Add Health took place in 1994-1995 (mean age $=16, \mathrm{SD}=2$ ).

Funded by the National Institutes of Health (NIH), Add Health is the primary source of information regarding development, health, and health behaviors of United States adolescents. Add Health has enrolled 12-21 years old adolescents who are representative of the United States adolescents. Publicly available data includes 6504 participants. The analytical sample for this study was non-Hispanic White adolescents that were a part of the public data. This study only included non-Hispanic Whites and excluded AAs, Hispanics, Asian Americans, and American Indians/Alaska Natives (AINAs).

\section{Sample and Sampling}

The Add Health study's samples in wave 1 were United States adolescents, who were between ages 12 and 21 years, and were non-institutionalized. The sample in this study was composed of 849 non-Hispanic White adolescents. We used the publicly available database of the National Longitudinal Study of Adolescent Health (Add Health) (McQueen et al., 2015).
The public database included half of the Add Health core sample who completed the baseline in-home interview and the oversample of AA adolescents who had a parent who were college graduates. The Add Health study used a multi-stage stratified probability sampling. The analytical sample was smaller than the original study because parental education was missing in a large proportion of participants, and most participants had not reported their grade for Math, English, Science, and History. Our analysis was limited to individuals who had complete data for our main variables.

\section{Study Variables \\ Parental Education Level}

Parents reported their level of education as a 9-level categorical variable. This variable was operationalized as a continuous measure, ranging from 1 to 9 , with a higher score indicating a higher level of education.

\section{Demographic Factors}

Age, grade, gender, and family structure (marital status of the parents) were the study covariates. Age was a continuous variable ranging from 12 to 21 . Grade was a continuous variable with a range from 7 to 12 . Age, grade, and gender were reported by the adolescents; however, family structure was reported by the parent.

\section{Neighborhood Quality}

Two items were used to measure subjective neighborhood quality. These items included "In this neighborhood, how big a problem is litter or trash on the streets and sidewalks?" and "In this neighborhood, how big a problem are drug dealers and drug users?" These items were both asked from parents. These items showed a positive, modest, and significant correlation $(r=0.45, p<0.001)$. Responses for each question were: no problem at all (1), a small problem (2), and a big problem (3). We calculated a mean score of the two items. Total score ranged from 1 to 3 , with a higher score indicating worse neighborhood quality (Mean $=1.53, \mathrm{SD}=0.53$ ). Although perceived presence of garbage and drugs in the neighborhood is not the best measure of neighborhood quality (Lang et al., 2008), these two items are frequently applied to measure objective and subjective neighborhood quality. Additionally, these two measures may reflect social disorder (Ross and Mirowsky, 1999). Perceived neighborhood is one of the main determinants of health and development (Ross and Mirowsky, 1999). Perceived neighborhood is also closely associated with objective measures of neighborhood quality (Williams et al., 2008; Osypuk et al., 2009; Assari, 2016).

\section{School Performance}

A cumulative score composed of self-reported grades of Math, English, Science, and History were conceptualized as overall school performance. Overall, 4 items were asked. Example item was "At the most recent grading period/last grading period in the spring, what was your grade in mathematics?" Similar items were used Reponses included did not take (1), took but did not grade (2), Ds (3), Cs (4), Bs (5), and As (6). Participants could also refuse 
to answer (did not include in the analysis). The overall school performance ranged from 4 to 24 , with a higher score indicating better school performance $($ Mean $=3.31, \mathrm{SD}=0.68)$.

\section{Statistical Analysis}

We applied SPSS 23.0 (IBM Corporation, Armonk, NY, United States) to analyze the data. For this report, we first explored the independent and joint distribution of all our study variables including parental education level, outcomes, and covariates. First, we ruled out multicollinearity between the variables. Age was strongly correlated with grade, so we needed to use one of the two variables. As our outcome (school performance) and predictor (parental education) was continuous, we performed linear regression for our multivariable analysis. We ran two regression models, both in the pooled sample. Model 1 included only main effects of parental education and the neighborhood perception variable but did not include the interaction term. Model 2 included the interaction term between perceived neighborhood quality and parental education level (i.e., multiplication of parental education and neighborhood quality). We did not center our variables because there was no risk of collinearity. From our linear regression models, we reported Beta (B) and 95\% Confidence Intervals (CI). $p$ values less than 0.05 were statistically significant.

\section{Ethics Statement}

All adolescent participants in the Add Health study provided written assent. Their parents provided written informed consent. The institutional review board of the University of North Carolina approved the Add Health study protocol. Charles R. Drew University of Medicine and Science institutional review board exempted the current secondary analysis from a full review.

\section{RESULTS}

\section{Descriptive Statistics}

Table 1 summarizes descriptive statistics. This study included 849 non-Hispanic White American adolescents who were between 12 and 21 years old. These students were in grades 7 to 12 .

\section{Bivariate Correlations}

Grade and age were negatively correlated with school performance. Higher neighborhood problem was associated with worse school performance (Table 2).

\section{Linear Regression Models}

Table 3 presents the summary of our two linear regression models in the pooled sample. In both these models, parental education level was the main independent variable, neighborhood quality was the moderator, and school performance was the outcome. While Model 1 only entered the main effects of our variables, Model 2 also included a statistical interaction term between parental educational level (1-9) and neighborhood quality.

Based on Model 1, parental education was not associated with better educational performance, however, worse neighborhood quality was associated with worse school performance. Based on
TABLE 1 | Descriptive statistics in the overall sample $(n=849)$.

\begin{tabular}{lrc}
\hline & Mean & Std. Deviation \\
\hline Age & 16.22 & 1.67 \\
Grade & 9.69 & 1.61 \\
Parent education (1-9) & 4.82 & 2.27 \\
Neighborhood problem (1-3) & 1.53 & 0.53 \\
School performance (Cumulative score) (1-4) & 3.31 & 0.68 \\
\hline & $\mathbf{N}$ & $\%$ \\
\hline Male & & 49.9 \\
Female & 424 & 50.1 \\
Male & 425 & \\
Parental marital status & & 56.5 \\
Not married & 480 & 43.3 \\
Married & 368 & \\
\hline
\end{tabular}

Model 2, a statistically significant interaction was found between neighborhood quality and parental educational attainment on school performance, meaning that the boosting effect of high parental educational attainment on adolescents' school performance is smaller for those who live in worse than better neighborhoods.

\section{DISCUSSION}

We found an interaction between perceived neighborhood quality and parental education level on non-Hispanic White youth school performance. This finding is suggestive of a smaller effect of parental education level on school performance of nonHispanic White youth in (subjectively) poor neighborhoods. Another interpretation of this finding is that poor neighborhoods have a larger detrimental effect on families with higher parental education. Both interpretations suggest that the effect of resource and context are multiplicative, with resource showing the highest level of effect at the best context (or context showing the largest effects at the top of the social strata). Our finding is indicative of the existence of place-based MDRs of parental educational attainment on youth school outcome.

The results suggested that ecological/cross level influences exist on youth educational development and neighborhood context has major implications on educational outcomes of the youth. According to the Bronfenbrenner's ecological system theory, child development is affected by their surrounding environment (Bronfenbrenner and Morris, 1998). We observed that some of the effects of place may not be direct but rather are due to place-based diminished returns of the SES Indicator.

Similar to past research showing that MDRs emerge due to race, ethnicity, and sexual minority status (Assari, 2018a), the new result suggests that MDRs phenomenon also applies to marginalization due to poor neighborhood. This means MDRs emerge as a result of marginalization, broadly defined, and not merely due to race, ethnicity, or sexual orientation. This study documented MDRs for non-Hispanic White youth in poor neighborhoods. The unique contribution of this study 
TABLE 2 | Correlation matrix $(n=849)$.

\begin{tabular}{|c|c|c|c|c|c|c|c|}
\hline & 1 & 2 & 3 & 4 & 5 & 6 & 7 \\
\hline 1 Gender (Male) & 1 & -0.07 & -0.02 & $-0.07^{\star}$ & $0.08^{\star}$ & 0.02 & 0.06 \\
\hline 2 Parental marital status (Married) & - & 1 & 0.04 & 0.05 & 0.01 & $-0.09^{\star \star}$ & -0.06 \\
\hline 3 Age (Years) (12-21) & - & - & 1 & $0.91^{\star \star}$ & -0.01 & 0.01 & $-0.30^{\star *}$ \\
\hline 4 School grade $(7-12)$ & - & - & - & 1 & 0.04 & -0.02 & $-0.34^{\star *}$ \\
\hline 5 Parental education (1-9) & - & - & - & - & 1 & $-0.16^{\star \star}$ & -0.01 \\
\hline 6 Poor neighborhood quality & - & - & - & - & - & 1 & -0.05 \\
\hline 7 School performance (English, Math, Science, and History) (1-4) & - & - & - & - & - & - & 1 \\
\hline
\end{tabular}

${ }^{*} p<0.05,{ }^{* *} p<0.001$.

TABLE 3 | Summary of linear regressions $(n=849)$.

\begin{tabular}{|c|c|c|c|c|c|c|c|c|c|c|c|c|c|c|}
\hline \multirow[b]{3}{*}{ Grade } & \multicolumn{7}{|c|}{ Model 1 Main effects } & \multicolumn{7}{|c|}{ Model 2 Model 1 + Interactions } \\
\hline & \multirow{2}{*}{$\begin{array}{l}\text { Beta } \\
-0.34\end{array}$} & \multirow{2}{*}{$\begin{array}{c}\text { B } \\
-0.14\end{array}$} & \multirow{2}{*}{$\begin{array}{l}\text { SE } \\
0.01\end{array}$} & \multicolumn{2}{|c|}{$95 \% \mathrm{Cl}$} & \multirow{2}{*}{$\begin{array}{c}\boldsymbol{t} \\
-10.73\end{array}$} & \multirow{2}{*}{$\begin{array}{c}\boldsymbol{p} \\
<0.001\end{array}$} & \multirow{2}{*}{$\begin{array}{l}\text { Beta } \\
-0.34\end{array}$} & \multirow{2}{*}{$\frac{\text { B }}{-0.14}$} & \multirow{2}{*}{$\begin{array}{l}\text { SE } \\
0.01\end{array}$} & \multicolumn{2}{|c|}{$95 \% \mathrm{Cl}$} & \multirow{2}{*}{$\begin{array}{c}\boldsymbol{t} \\
-10.72\end{array}$} & \multirow{2}{*}{$\begin{array}{c}\boldsymbol{p} \\
<0.001\end{array}$} \\
\hline & & & & -0.17 & -0.12 & & & & & & -0.17 & -0.12 & & \\
\hline Gender (Male) & 0.04 & 0.05 & 0.04 & -0.03 & 0.13 & 1.19 & 0.234 & 0.04 & 0.05 & 0.04 & -0.03 & 0.14 & 1.21 & 0.226 \\
\hline $\begin{array}{l}\text { Parental marital } \\
\text { status (Married) }\end{array}$ & -0.05 & -0.07 & 0.04 & -0.15 & 0.02 & -1.55 & 0.121 & -0.05 & -0.06 & 0.04 & -0.15 & 0.02 & -1.46 & 0.144 \\
\hline Parental education & -0.01 & 0.00 & 0.01 & -0.02 & 0.02 & -0.16 & 0.872 & 0.19 & 0.06 & 0.03 & 0.00 & 0.11 & 1.94 & 0.052 \\
\hline $\begin{array}{l}\text { Neighborhood } \\
\text { quality (Problems) }\end{array}$ & -0.06 & -0.08 & 0.04 & -0.16 & 0.00 & -2.02 & 0.043 & 0.07 & 0.09 & 0.09 & -0.09 & 0.27 & 1.00 & 0.317 \\
\hline $\begin{array}{l}\text { Neighborhood quality } \\
\text { (Problems) } \times \text { Parental } \\
\text { education }\end{array}$ & - & - & - & - & - & - & - & -0.23 & -0.04 & 0.02 & -0.08 & 0.00 & -2.11 & 0.035 \\
\hline Intercept & & 4.82 & 0.16 & 4.51 & 5.12 & 30.95 & $<0.001$ & - & 4.55 & 0.20 & 4.16 & 4.94 & 22.67 & $<0.001$ \\
\hline
\end{tabular}

is that it suggests that MDRs can even be seen in socially disadvantaged White youth.

Previous research has shown smaller effects of parental education on AA and Hispanic youth GPA (Assari, 2019d; Assari et al., 2020a), school attainment (Assari, 2018b), and school bonding (Assari, 2019c). This is probably the first study that reports place-based MDRs for White youth.

We found evidence supportive of neighborhood quality as a potential cause of MDRs in non-Hispanic White youth. What was previously known was the role of race/ethnicity as a source of MDRs. Parental education show smaller effects for marginalized people across domains (Assari et al., 2020a) even when race is not a factor. For example, parental education has shown smaller effects on Attention Deficit Hyperactivity Disorder for AAs than non-Hispanic Whites (Assari and Caldwell, 2019). The same is shown for mental health problems (Assari, 2018c) such as depression (Assari and Caldwell, 2018; Assari et al., 2018d). Parental education has also shown smaller effects on impulse control (Assari et al., 2018a), smoking (Bachman et al., 2011), and aggression (Assari et al., 2020a) for AA and Hispanic youth than their White counterparts. As shown in the literature, MDRs phenomenon also applies to non-academic outcomes such as mental health (Assari and Caldwell, 2018; Assari et al., 2018d) and health behaviors (Bachman et al., 2011).

As similar patterns are observed across SES resources, outcomes, and definitions of marginalization, MDRs are believed to be a consequence of societal forces (Assari, 2017, 2018a). Such social forces would reduce the efficiency of the effects of available resources on outcomes. Social stratification, segregation, racism, labor market discrimination, and poor education quality in urban areas may be among upstream mechanisms that can interfere with the process of translation of available social determinants on various outcomes across various marginalized groups. While racism may operate for AAs, high risk neighborhoods may impose all groups (regardless of race) to the risk of MDRs. The unique contribution of this study is to suggest that poor neighborhood quality may be one of the contextual mechanisms by which SES loses its effect for marginalized people, even when they are non-Hispanic White.

This study documented MDRs of parental educational attainment on school performance for 12-21 years old nonHispanic White adolescents. MDRs are not limited to adolescents as they are also found for adults (Bachman et al., 2011). These patterns are not merely seen for parental education level (Assari, 2018c) as similar patterns are shown for own education (Assari, 2019a,b). While MDRs are shown for (Assari et al., 2020b) AAs (Assari et al., 2018a,b,e), Hispanics (Assari et al., 2020a), and American Indians and Alaska Natives (AIANs) (Assari and Bazargan, 2019b), this study adds to this literature by showing that MDRs may also be relevant to non-Hispanic Whites. We believe that this is a major step forward in our understanding about the social conditions that are associated with MDRs.

Relative to families that live in better neighborhoods, youth who live in poor quality neighborhoods show poor 
school performance, even when they have highly educated parents. Living in poor quality neighborhoods may reflect social marginalization. However, it is yet unknown which neighborhood features better reflect structural and contextual factors that cause MDRs. The same pattern is shown for ethnic minority youth with highly educated parents (Assari et al., 2020a). While past research shows that MDRs can emerge due to race (Assari et al., 2018e), ethnicity (Assari et al., 2019), and sexual orientation (Assari and Bazargan, 2019a), this study suggests that it may also be shaped by place. As a result of such MDRs, youth develop undesired outcomes despite having highly educated parents.

As a result of MDRs, we see worse than expected outcomes in middle class people who have been marginalized. To be more specific, the findings of this study suggests that we should expect worse than expected educational outcomes in middleclass non-Hispanic White families who have access to human capital (education) but for some reasons live in undesirable neighborhoods. Thus, inequalities and disparities impact people across all levels of education (social class), and such inequalities are not limited to lack of access to education (lower social class) but is sometimes shaped across SES strata. The 2nd contribution of this study is that MDRs might be seen due to contextual (social) rather than individual behaviors. That is, individual level resources may fail to protect people in poor contexts. The results suggest that place matters but one of the mechanisms of the effects of place may be through reducing the marginal return of SES indicators. In other terms, while some parts of the inequalities are due to lack of access, some other parts might be due to weakened effects of available resources in those with access to resources (in poor contexts). As shown here, middle class White families who live in places with societal and structural barriers may not be able to most effectively leverage their family resources and secure maximum outcomes for their youth.

\section{Limitations}

No study is without limitations. Due to a cross-sectional design, we cannot make any causal inferences. The reason we have taken a causal language in this paper is to help articulate our big picture framework. The results should be read as correlational rather than causal. This study only included non-Hispanic Whites. Although this can be seen as a problem, it may also serve as a main strength of the paper. As mentioned above, this is the first paper to show that MDRs may also apply to non-Hispanic Whites. Our decision to limit the sample to Whites was also because MDRs emerge as a result of race/ethnicity, and we did not want to complicate the study with other sources of MDRs due to race/ethnicity. Future research should also include similar interactions for AAs, Hispanics, Asians, AINAs, and Asian Americans. We only included parental education level as a SES indicator. Other family SES indicators such as household income, employment, wealth, and employment should be studied in the future attempts. While we measured subjective neighborhood quality, it is unknown what objective structural and contextual factor accounts for our findings. All study variables were individual level, and more work is needed across various levels of data.

Some of the limitations of this study was because we used existing data. So, we were bounded with the data which were available. In this study we did not have access to the zip code data. Future research may explore the type of contextual and neighborhood factors than can reduce returns of resources for marginalized families. Neighborhood quality in this study was subjective rather than objective. Segregation, density of poverty, school quality, and physical and social neighborhood disorder may all have some role. Despite these short comings, this study still contributes to the existing literature by extending MDRs from a study of race/ethnicity to contextual causes of poor outcomes. A large sample size, a random sampling, multiple ethnic groups, and multiple outcomes studied resulted in knowledge which is generalizable to the United States adolescents.

\section{CONCLUSION}

In the United States, adolescents who live in worse neighborhoods are at a relative disadvantage compared to their counterparts who live in better neighborhoods regarding the magnitude of the effect of their parental education level on their school performance. This study suggested that MDRs are not specific to racial and ethnic minority groups and also hold for non-Hispanic Whites. In this paper we found placebased diminished returns or SES which is similar to race-based diminished returns. All of these MDRs are due to some type of social stratification.

\section{DATA AVAILABILITY STATEMENT}

The datasets generated for this study are available on request to the corresponding author.

\section{ETHICS STATEMENT}

All adolescent participants in the Add Health study provided written assent. Their parents provided written informed consent. The institutional review board of the University of North Carolina approved the Add Health study protocol. Charles R. Drew University of Medicine and Science institutional review board exempted the current secondary analysis from a full review.

\section{AUTHOR CONTRIBUTIONS}

SA developed the MDRs theory, conceptualized the study, analyzed the data, prepared the first draft of the manuscript, and acquired the funding, full access to all the data in the study and takes responsibility for the integrity of the data and the accuracy of the data analysis. $\mathrm{MB}, \mathrm{SB}$, and $\mathrm{CC}$ contributed to the revision and conceptualization of the study. All authors approved the final draft of manuscript. 


\section{FUNDING}

The research was reported in this publication was supported by the National Institutes of Health (NIH) awards: U54MD008149, R25 MD007610, 5S21MD000103, and U54CA229974. The funder

\section{REFERENCES}

Albrecht, S. S., and Gordon-Larsen, P. (2013). Ethnic differences in body mass index trajectories from adolescence to adulthood: a focus on Hispanic and Asian subgroups in the United States. PLoS One 8:e72983. doi: 10.1371/journal.pone. 0072983

Ali, F. R. M., and Elsayed, M. A. A. (2018). The effect of parental education on child health: Quasi-experimental evidence from a reduction in the length of primary schooling in Egypt. Health Econ. 27, 649-662. doi: 10.1002/hec 3622

Appleton-Arnaud, J. (2008). Parental education key to health for parents and children. Prev. Chronic Dis. 5:A68;author reply A69.

Arellano, C. M., Chavez, E. L., and Deffenbacher, J. L. (1998). Alcohol use and academic status among Mexican American and white non-Hispanic adolescents. Adolescence 33, 751-760.

Assari, S. (2016). Perceived neighborhood safety better predicts risk of mortality for whites than blacks. J. Racial Ethn. Health Disparities doi: 10.1007/s40615016-0297-x [Epub ahead of print].

Assari, S. (2017). Unequal gain of equal resources across racial groups. Int. J. Health Policy Manag. 7, 1-9. doi: 10.15171/ijhpm.2017.90

Assari, S. (2018a). Health disparities due to diminished return among black Americans: public policy solutions. Soc. Issues Policy Rev. 12, 112-145. doi: 10.1111/sipr.12042

Assari, S. (2018b). Parental education attainment and educational upward mobility; role of race and gender. Behav. Sci. (Basel) 8:107. doi: 10.3390/bs8110107

Assari, S. (2018c). Parental educational attainment and mental well-being of college students; diminished returns of blacks. Brain Sci. 8:193. doi: 10.3390/ brainsci8110193

Assari, S. (2019a). Education attainment and obesity differential returns based on sexual orientation. Behav. Sci. (Basel) 9:E16. doi: 10.3390/bs9020016

Assari, S. (2019b). Educational attainment and exercise frequency in American women; blacks' diminished returns. Womens Health Bull. 6:e87413.

Assari, S. (2019c). Family socioeconomic position at birth and school bonding at age 15; blacks' diminished returns. Behav. Sci. (Basel) 9:E26. doi: 10.3390/ bs 9030026

Assari, S. (2019d). Parental educational attainment and academic performance of American college students; blacks' diminished returns. J. Health Econ. Dev. 1, 21-31.

Assari, S., and Bazargan, M. (2019a). Education level and cigarette smoking: diminished returns of lesbian, gay and bisexual individuals. Behav. Sci. (Basel) 9:103. doi: 10.3390/bs9100103

Assari, S., and Bazargan, M. (2019b). Protective effects of educational attainment against cigarette smoking; diminished returns of American Indians and Alaska Natives in the national health interview survey. Int. J. Travel Med. Glob. Health 7, 105-110. doi: 10.15171/IJTMGH.2019.22

Assari, S., Bazargan, M., and Caldwell, C. H. (2020a). Association between parental educational attainment and youth outcomes and role of race/ethnicity. JAMA Netw. Open 2:e1916018. doi: 10.1001/jamanetworkopen.2019.16018

Assari, S., Boyce, S., Bazargan, M., and Caldwell, C. H. (2020b). Mathematical performance of American Youth: diminished returns of educational attainment of asian-american parents. Educ. Sci. 10:32. doi: 10.3390/educsci10020032

Assari, S., and Caldwell, C. H. (2017). Mental health service utilization among black youth; psychosocial determinants in a national sample. Children (Basel) 4:40 doi: 10.3390/children4050040

Assari, S., and Caldwell, C. H. (2018). High risk of depression in high-income African American boys. J. Racial Ethn. Health Disparities 5, 808-819. doi: 10. 1007/s40615-017-0426-1

Assari, S., and Caldwell, C. H. (2019). Family income at birth and risk of attention deficit hyperactivity disorder at age 15: racial differences. Children (Basel) 6:E10 doi: 10.3390/children6010010 did not interfere with the design and conduct of the study; collection, management, analysis, and interpretation of the data; preparation, review, or approval of the manuscript; and decision to submit the manuscript for publication. Health study is supported by multiple NIH awards including P01-HD3192.3.

Assari, S., Caldwell, C. H., and Bazargan, M. (2019). Association between parental educational attainment and youth outcomes and role of race/ethnicity. JAMA Netw. Open 2:e1916018.

Assari, S., Caldwell, C. H., and Mincy, R. (2018a). Family socioeconomic status at birth and youth impulsivity at age 15; blacks' diminished return. Children (Basel) 5:E58. doi: 10.3390/children5050058

Assari, S., Caldwell, C. H., and Mincy, R. B. (2018b). Maternal educationa attainment at birth promotes future self-rated health of white but not black youth: a 15-year cohort of a national sample. J. Clin. Med. 7:E93. doi: 10.3390/ jcm7050093

Assari, S., Caldwell, C. H., and Zimmerman, M. A. (2018c). Family structure and subsequent anxiety symptoms; minorities' diminished return. Brain Sci. 8:E97. doi: 10.3390/brainsci8060097

Assari, S., and Hani, N. (2018). Household income and children's unmet dental care need; blacks' diminished return. Dent. J. (Basel) 6:E17. doi: 10.3390/dj6020017

Assari, S., and Lankarani, M. M. (2016). Reciprocal associations between depressive symptoms and mastery among older adults; black-white differences. Front. Aging Neurosci. 8:279. doi: 10.3389/fnagi.2016.00279

Assari, S., Lankarani, M. M., and Caldwell, C. H. (2018d). Does discrimination explain high risk of depression among high-income African American men? Behav. Sci. (Basel) 8:E40. doi: 10.3390/bs8040040

Assari, S., Thomas, A., Caldwell, C. H., and Mincy, R. B. (2018e). Blacks' diminished health return of family structure and socioeconomic status; 15 years of follow-up of a national urban sample of youth. J. Urban Health 95, 21-35. doi: 10.1007/s11524-017-0217-3

Bachman, J. G., O’Malley, P. M., Johnston, L. D., Schulenberg, J. E., and Wallace, J. M. (2011). Racial/ethnic differences in the relationship between parental education and substance use among U.S. 8th-, 10th-, and 12th-grade students: findings from the Monitoring the Future project. J. Stud. Alcohol Drugs 72, 279-285. doi: 10.15288/jsad.2011.72.279

Basch, C. E. (2011). Aggression and violence and the achievement gap among urban minority youth. J. Sch. Health 81, 619-625. doi: 10.1111/j.1746-1561. 2011.00636.x

Benjet, C., Borges, G., Medina-Mora, M. E., Zambrano, J., Cruz, C., and Mendez, E. (2009). Descriptive epidemiology of chronic childhood adversity in Mexican adolescents. J. Adolesc. Health 45, 483-489. doi: 10.1016/j.jadohealth.2009. 03.002

Blok, D. J., de Vlas, S. J., Bakker, R., and van Lenthe, F. J. (2015). Reducing income inequalities in food consumption: explorations with an agent-based model. Am. J. Prev. Med. 49, 605-613. doi: 10.1016/j.amepre.2015.03.042

Bronfenbrenner, U., and Morris, P. A. (1998). "The ecology of developmental processes," in (Orgs.), Handbook of Child Psychology: Theoretical Models of Human Development, Vol. 1, eds W. Damon, and R. M. Lerner (New York, NY: John Wiley), 993-1028.

Butler, A. M. (2017). Social determinants of health and racial/ethnic disparities in type 2 diabetes in youth. Curr. Diab. Rep. 17:60. doi: 10.1007/s11892-0170885-0

Carlo, G., Crockett, L. J., Carranza, M. A., and Martinez, M. M. (2011) Understanding ethnic/racial health disparities in youth and families in the US. Nebr. Symp. Motiv. 57, 1-11. doi: 10.1007/978-1-4419-7092-3_1

Chavous, T. M., Rivas-Drake, D., Smalls, C., Griffin, T., and Cogburn, C. (2008). Gender matters, too: the influences of school racial discrimination and racial identity on academic engagement outcomes among African American adolescents. Dev. Psychol. 44:637. doi: 10.1037/0012-1649.44.3.637

Davis-Kean, P. E. (2005). The influence of parent education and family income on child achievement: the indirect role of parental expectations and the home environment. J. Family Psychol. 19:294. doi: 10.1037/0893-3200.19.2.294

Guglielmo, D., Gazmararian, J. A., Chung, J., Rogers, A. E., and Hale, L. (2018). Racial/ethnic sleep disparities in US school-aged children and adolescents: a review of the literature. Sleep Health 4, 68-80. doi: 10.1016/j.sleh.2017.09.005 
Hyland, A., Ambrose, B. K., Conway, K. P., Borek, N., Lambert, E., Carusi, C., et al. (2017). Design and methods of the population assessment of tobacco and health (PATH) study. Tob. Control 26, 371-378. doi: 10.1136/tobaccocontrol2016-052934

Jones, A. (2018). Race, socioeconomic status, and health during childhood: a longitudinal examination of racial/ethnic differences in parental socioeconomic timing and child obesity risk. Int. J. Environ. Res. Public Health 15:E728. doi: 10.3390/ijerph15040728

Lang, I. A., Llewellyn, D. J., Langa, K. M., Wallace, R. B., Huppert, F. A., and Melzer, D. (2008). Neighborhood deprivation, individual socioeconomic status, and cognitive function in older people: analyses from the English longitudinal study of ageing. J. Am. Geriatr. Soc. 56, 191-198. doi: 10.1111/j.1532-5415.2007. 01557.x

Lau, M., Lin, H., and Flores, G. (2012). Racial/ethnic disparities in health and health care among U.S. adolescents. Health Serv. Res. 47, 2031-2059. doi: 10.1111/j. 1475-6773.2012.01394.x

Li, F., Harmer, P., Cardinal, B. J., Bosworth, M., and Johnson-Shelton, D. (2009). Obesity and the built environment: does the density of neighborhood fastfood outlets matter? Am. J. Health Promot. 23, 203-209. doi: 10.4278/ajhp. 071214133

Mackenbach, J. D., Lakerveld, J., van Oostveen, Y., Compernolle, S., De Bourdeaudhuij, I., Bardos, H., et al. (2017). The mediating role of social capital in the association between neighbourhood income inequality and body mass index. Eur. J. Public Health 27, 218-223. doi: 10.1093/eurpub/ckw157

Malhotra, K., Shim, R., Baltrus, P., Heiman, H. J., Adekeye, O., and Rust, G. (2015). Racial/ethnic disparities in mental health service utilization among youth participating in negative externalizing behaviors. Ethn. Dis. 25, 123-129.

McQueen, M. B., Boardman, J. D., Domingue, B. W., Smolen, A., Tabor, J., KilleyaJones, L., et al. (2015). The national longitudinal study of adolescent to adult health (add health) sibling pairs genome-wide data. Behav. Genet. 45, 12-23. doi: 10.1007/s10519-014-9692-4

Mercy, J. A., and Steelman, L. C. (1982). Familial influence on the intellectual attainment of children. Am. Sociological Rev. 47, 532-542.

Messiah, S. E., Arheart, K. L., Lopez-Mitnik, G., Lipshultz, S. E., and Miller, T. L. (2013). Ethnic group differences in cardiometabolic disease risk factors independent of body mass index among American youth. Obesity (Silver Spring) 21, 424-428. doi: 10.1002/oby.20343

Osypuk, T. L., Diez Roux, A. V., Hadley, C., and Kandula, N. R. (2009) Are immigrant enclaves healthy places to live? The multi-ethnic study of atherosclerosis. Soc. Sci. Med. 69, 110-120. doi: 10.1016/j.socscimed.2009. 04.010

Patel, O., Shahulhameed, S., Shivashankar, R., Tayyab, M., Rahman, A., Prabhakaran, D., et al. (2017). Association between full service and fast food restaurant density, dietary intake and overweight/obesity among adults in Delhi, India. BMC Public Health 18:36. doi: 10.1186/s12889-017-4598-8
Prentice, A. M., and Jebb, S. A. (2003). Fast foods, energy density and obesity: a possible mechanistic link. Obes. Rev. 4, 187-194. doi: 10.1046/j.1467-789x. 2003.00117.x

Ross, C. E., and Mirowsky, J. (1999). Disorder and decay: the concept and measurement of perceived neighborhood disorder. Urban Aff. Rev. 34, 412-432. doi: $10.1177 / 10780879922184004$

Rossen, L. M., and Schoendorf, K. C. (2012). Measuring health disparities: trends in racial-ethnic and socioeconomic disparities in obesity among 2- to 18-year old youth in the United States, 2001-2010. Ann. Epidemiol. 22, 698-704. doi: 10.1016/j.annepidem.2012.07.005

Sisco, S., Gross, A. L., Shih, R. A., Sachs, B. C., Glymour, M. M. Bangen, K. J., et al. (2015). The role of early-life educational quality and literacy in explaining racial disparities in cognition in late life. J. Gerontol. B Psychol. Sci. Soc. Sci. 70, 557-567. doi: 10.1093/geronb/ gbt133

Tourangeau, R., Yan, T., Sun, H., Hyland, A., and Stanton, C. A. (2018). Population assessment of tobacco and health (PATH) reliability and validity study: selected reliability and validity estimates. Tob. Control 28, 663-668. doi: 10.1136/ tobaccocontrol-2018-054561

Wallace, J. M. Jr, Vaughn, M. G., Bachman, J. G., O’Malley, P. M., Johnston, L. D., and Schulenberg, J. E. (2009). Race/ethnicity, socioeconomic factors, and smoking among early adolescent girls in the United States. Drug Alcohol Depend. 104(Suppl. 1), S42-S49. doi: 10.1016/j.drugalcdep.2009. 06.007

Williams, D. R., Costa, M. V., Odunlami, A. O., and Mohammed, S. A. (2008). Moving upstream: how interventions that address the social determinants of health can improve health and reduce disparities. J. Public Health Manag. Pract. 14(Suppl.), S8-S17. doi: 10.1097/01.PHH.0000338382. 36695.42

Wills, T. A., McNamara, G., and Vaccaro, D. (1995). Parental education related to adolescent stress-coping and substance use: development of a mediational model. Health Psychol. 14, 464-478. doi: 10.1037//0278-6133.14. 5.464

Conflict of Interest: The authors declare that the research was conducted in the absence of any commercial or financial relationships that could be construed as a potential conflict of interest.

Copyright (c) 2020 Assari, Boyce, Bazargan, Caldwell and Zimmerman. This is an open-access article distributed under the terms of the Creative Commons Attribution License (CC BY). The use, distribution or reproduction in other forums is permitted, provided the original author(s) and the copyright owner(s) are credited and that the original publication in this journal is cited, in accordance with accepted academic practice. No use, distribution or reproduction is permitted which does not comply with these terms. 